\title{
MinI-REVIEW
}

\section{Find and replace: editing human genome in pluripotent stem cells}

\author{
Huize Pan ${ }^{1 *}$, Weiqi Zhang ${ }^{1 *}$, Weizhou Zhang ${ }^{2 凶}$, Guang-Hui Liu ${ }^{1 凶}$ \\ ${ }^{1}$ National Laboratory of Biomacromolecules, Institute of Biophysics, Chinese Academy of Sciences, Beijing 100101, China \\ 2 Laboratory of Gene Regulation and Signal Transduction, Department of Pharmacology, School of Medicine, University of \\ California, San Diego, La Jolla, CA 92093, USA \\ $₫$ Correspondence: w4zhang@ucsd.edu (W. Zhang), ghliu@ibp.ac.cn (G.-H. Liu) \\ Received November 20, 2011 Accepted December 4, 2011
}

\begin{abstract}
Genetic manipulation of human pluripotent stem cells (hPSCs) provides a powerful tool for modeling diseases and developing future medicine. Recently a number of independent genome-editing techniques were developed, including plasmid, bacterial artificial chromosome, adeno-associated virus vector, zinc finger nuclease, transcription activator-like effecter nuclease, and helper-dependent adenoviral vector. Gene editing has been successfully employed in different aspects of stem cell research such as gene correction, mutation knock-in, and establishment of reporter cell lines (Raya et al., 2009; Howden et al., 2011; Li et al., 2011; Liu et al., 2011b; Papapetrou et al., 2011; Sebastiano et al., 2011; Soldner et al., 2011; Zou et al., 2011a). These techniques combined with the utility of hPSCs will significantly influence the area of regenerative medicine.
\end{abstract}

KEYWORDS gene targeting, gene editing, gene correction, pluripotent stem cell

\section{INTRODUCTION}

Gene manipulation by classic homologous recombination is inefficient and laborious in human pluripotent stem cells (hPSCs), which has hampered the development of hPSCsderived disease model and therapeutic applications. In 2003, Thomson group successfully knocked out HPRT1 gene and knocked in a reporter at POU5F1 locus in human embryonic stem cells (hESCs) using an electroporation approach (Zwaka and Thomson, 2003). A few other research groups also successfully obtained gene-modified cell lines with this conventional approach, nevertheless with extremely low efficiency (Urbach et al., 2004; Costa et al., 2007; Irion et al., 2007; Davis et al., 2008; Di Domenico et al., 2008; Bu et al., 2009; Kamei et al., 2009; Ruby and Zheng, 2009; Xue et al., 2009; Bu et al., 2010; Buecker et al., 2010; Fischer et al., 2010; Goulburn et al., 2011). To overcome technical limitations, novel gene editing strategies have been developed to enhance targeting efficiency in hPSCs, such as bacterial artificial chromosome (BAC) (Song et al., 2010), adenoassociated virus vector (AAV) (Khan et al., 2010; Asuri et al., 2011), zinc finger nuclease (ZFN) (Lombardo et al., 2007; Hockemeyer et al., 2009; Zou et al., 2009), transcription activator-like effecter nuclease (TALEN) (Cermak et al., 2011; Hockemeyer et al., 2011; Miller et al., 2011; Mussolino et al., 2011; Zhang et al., 2011), and helper-dependent adenoviral vector (HDAdV) (Suzuki et al., 2008; Li et al., 2011; Liu et al., $2011 b)$. Here we focus on comparing cons and pros of the above novel techniques to explore their potential for efficient and safe gene targeting in hPSCs. The applications and properties of novel gene editing tools are summarized in Table 1.

\section{BAC}

Recently, two independent groups reported successful gene targeting in hPSCs using BAC-based strategy (Song et al., 2010; Howden et al., 2011). Song et al. constructed BAC vectors containing long homologous DNA fragments to target human ATM and TP53 alleles with a relative high efficiency $(\sim 27 \%)$ after 2 rounds of electroporation and drug selection (Song et al., 2010). Thomson group used a similar BACbased approach and corrected a single base-pair mutation in human induced pluripotent stem cells (hiPSCs) from a patient

\footnotetext{
*These authors contributed equally to the work.
} 
Table 1 Summary of recently developed gene editing tools

\begin{tabular}{|c|c|c|c|c|}
\hline Name & Targeted genomic loci & Cell type & $\begin{array}{l}\text { Mutation/ } \\
\text { Insertion/Correction }\end{array}$ & References \\
\hline \multirow[t]{11}{*}{ Plasmid } & HPRT1 & hESCs, hiPSCs & $\begin{array}{l}\text { Mutation/Correction } \\
\text { /Insertion }\end{array}$ & $\begin{array}{l}\text { Zwaka and Thomson, 2003; Urbach et al., } \\
\text { 2004; Di Domenico et al, 2008; Sakurai et } \\
\text { al., 2010; Buecker et al., } 2010\end{array}$ \\
\hline & ОСT3/4 & hESCs & Insertion & $\begin{array}{l}\text { Zwaka and Thomson, 2003; Braam et al., } \\
\text { 2008; Kamei et al., } 2009\end{array}$ \\
\hline & Three loci & hESCs & Insertion & Costa et al., 2007 \\
\hline & ROSA26 & hESCs & Insertion & Irion et al., 2007 \\
\hline & MIXL1 & hESCs & Insertion & Davis et al., 2008 \\
\hline & ISL1 & hESCs & Insertion & Bu et al., 2009 \\
\hline & Fezf2 & hESCs & Insertion & Ruby and Zheng, 2009 \\
\hline & Olig2 & hESCs & Insertion & Xue et al., 2009 \\
\hline & BAF250a (ARID1A) & hESCs & Mutation & Bu et al., 2010 \\
\hline & NANOG & hESCs & Insertion & Fischer et al., 2010 \\
\hline & $N K X 2-5$ & hESCs & Insertion & Elliott et al., 2011 \\
\hline $\begin{array}{l}\text { Baculoviral } \\
\text { vector }\end{array}$ & AAVS1 & hESCs & Insertion & Ramachandra et al., 2011 \\
\hline \multirow[t]{4}{*}{ AAV } & HPRT1 & hESCs, hiPSCs & $\begin{array}{l}\text { Insertion/Mutation/ } \\
\text { Correction }\end{array}$ & Mitsui et al., 2009; Khan et al., 2010 \\
\hline & NANOG & hESCs, hiPSCs & Insertion & Mitsui et al., 2009 \\
\hline & HGMA1 & hESCs & Insertion & Khan et al., 2010 \\
\hline & Type I collagen & Mesenchymal stem cells & Correction & Deyle et al., 2011 \\
\hline \multirow[t]{4}{*}{ BAC } & ATM & hESCs & Mutation & Song et al., 2010 \\
\hline & TP53 & hESCs & Mutation & Song et al., 2010 \\
\hline & HPRT1 & hESCs & Mutation & Song et al., 2010 \\
\hline & OAT & hiPSCs & Correction & Howden et al., 2011 \\
\hline \multirow[t]{12}{*}{ ZFN } & GFP & hESCs & Correction & Zou et al., 2009 \\
\hline & PIG-A & hESCs, hiPSCs & $\begin{array}{l}\text { Mutation / } \\
\text { Correction }\end{array}$ & Zou et al., 2009 \\
\hline & ОСТ3/4 & hESCs & Insertion & Hockemeyer et al., 2009 \\
\hline & AAVS1 & hESCs, hiPSCs & Insertion & $\begin{array}{l}\text { Hockemeyer et al., 2009; Lombardo et al., } \\
2011\end{array}$ \\
\hline & PITX3 & hESCs, hiPSCs & Insertion & Hockemeyer et al., 2009 \\
\hline & CCR5 & $\begin{array}{l}\text { Hematopoietic K- } 562 \text { cells, } \\
\text { Jurkat cells, lymphoblastoid } \\
\text { cells, cord blood CD34+ } \\
\text { hematopoietic progenitor } \\
\text { cells, hESCs }\end{array}$ & Insertion & $\begin{array}{l}\text { Lombardo et al., 2007; Lombardo et al., } \\
2011\end{array}$ \\
\hline & $I L 2 R G$ & $\begin{array}{l}\text { K-562 cells, } \\
\text { lymphoblastoid cells, } \\
\text { HEK293 }\end{array}$ & Insertion/Correction & Lombardo et al., 2007 \\
\hline & TP53, DNMT1 shRNA & hESCs & Insertion & DeKelver et al., 2010 \\
\hline & gp91 $1^{\text {phox }}$ & hiPSCs & Correction & Zou et al., 2011b \\
\hline & a-Synuclein $(\alpha-S Y N)$ & hESCs, hiPSCs & $\begin{array}{l}\text { Correction/ } \\
\text { Mutation }\end{array}$ & Soldner et al., 2011 \\
\hline & $\beta$-globin $(H B B)$ & hiPSCs & Correction & Zou et al., 2011a \\
\hline & $\alpha_{1}$-antitrypsin $(A 1 A T)$ & hiPSCs & Correction & Yusa et al., 2011 \\
\hline HDAdV & HPRT1 & hESCs & Mutation & Suzuki et al., 2008 \\
\hline
\end{tabular}


(Continued)

\begin{tabular}{|c|c|c|c|c|}
\hline Name & Targeted genomic loci & Cell type & $\begin{array}{l}\text { Mutation/ } \\
\text { Insertion/Correction }\end{array}$ & References \\
\hline & LMNA & $\begin{array}{l}\text { hiPSCs, Olfactory } \\
\text { ectomesenchymal stem cells }\end{array}$ & Correction & Liu et al., 2011b \\
\hline & $\beta$-globin $(H B B)$ & hiPSCs & Correction & Li et al., 2011 \\
\hline \multirow[t]{9}{*}{ TALEN } & CCR5 & HEK293T, K562 & Insertion/Mutation & Miller et al., 2011; Mussolino et al., 2011 \\
\hline & IL2RG & HEK293T & Insertion & Mussolino et al., 2011 \\
\hline & NTF3 & HEK293 & Mutation & Miller et al., 2011 \\
\hline & OCT4 exon 1 & hESCs, hiPSCs & Insertion & Hockemeyer et al., 2011 \\
\hline & OCT4 STOP codon & hESCs, hiPSCs & Insertion & Hockemeyer et al., 2011 \\
\hline & AAVS1 & hESCs, hiPSCs & Insertion & Hockemeyer et al., 2011 \\
\hline & PITX3 exon 1 & hESCs, hiPSCs & Insertion & Hockemeyer et al., 2011 \\
\hline & PITX3 STOP codon & hESCs, hiPSCs & Insertion & Hockemeyer et al., 2011 \\
\hline & HPRT1 & HEK293T & Mutation & Cermak et al., 2011 \\
\hline
\end{tabular}

hESCs, human embryonic stem cells; hPSCs, human pluripotent stem cells; hiPSCs, human induced pluripotent stem cells; AAV, adeno-associated virus vector; BAC, bacterial artificial chromosome; ZFN, zinc finger nuclease; HDAdV, helper-dependent adenoviral vector; TALEN, transcription activator-like effecter nuclease.

with gyrate atrophy after two rounds of homologous recombination (Howden et al., 2011). BAC vectors seem to represent a simple and feasible method to edit genome in hPSCs. They are more efficient to transfer long homologous arms with better accuracy relative to classic homologous recombination in hPSCs. However, there are certain limitations of BACbased gene targeting including low delivery efficiency due to its large size, potential intracellular degradation of long naked BAC DNA, and difficulty to design probes or primers to confirm gene targeting by Southern blot and long PCR.

\section{ZFN}

ZFNs are a class of artificial nucleases that stimulate frequency of gene editing by producing double-strand breaks at specified DNA sequence. Theoretically, ZFNs could be used to create gene knock-ins and knock-outs into any gene loci in various somatic cell types. In 2007, Lombardo et al. used a vector based on integrase-deficient lentivirus (IDLV) to transfer ZFN and specific donor DNA into hESCs and human lymphoblastoid cells and successfully integrated 800-bp cDNA into IL2RG locus, mutations of which lead to $X$-linked severe combined immunodeficiency (SCID-X1). In this study, they observed $5 \%$ targeting efficiency in hESCs without drug selection (Lombardo et al., 2007). Thereafter, ZFNs were widely used to create or correct specific mutations in hPSCs (Hockemeyer et al., 2009; Zou et al., 2009; Asuri et al., 2011; DeKelver et al., 2010; Lombardo et al., 2011; Mussolino et al., 2011; Sebastiano et al., 2011; Soldner et al., 2011; Yusa et al., 2011; Zou et al., 2011a, 2011b). In these studies, hPSCs retained characterizations of 'stemness' and normal cell karyotype while achieving permanent and heritable gene modifications at specific endogenous loci. Recently, Jaenisch group corrected an $\alpha$-SYNUCLEIN point mutation in
Parkinson's disease patient-derived hiPSCs (Soldner et al., 2011). In this study, > 1\% efficiency with corrected $\alpha$-SYNUCLEIN at both alleles was achieved in the same settings without any genomic "scar" caused by selection markers or molecular footprints. More recently, a novel gene targeting method by combining a piggyBAC transposon and ZFN was reported to correct defected $\alpha_{1}$-ANTITRYPSIN gene in patient-derived hiPSCs in the absence of genomic "scars" (Yusa et al., 2011). Compared to plasmids- or BAC-based gene targeting strategies, which require two rounds of homologous recombination to modify both alleles, ZFNsmediated homologous recombination allows biallelic edits at the same time. Therefore, ZFN strategy circumvents the necessity of repeated editing process, improves editing efficiency and saves time for researchers. In addition, ZFNs are able to efficiently target silenced genomic loci in hPSCs (Hockemeyer et al., 2009).

ZFNs-based gene targeting techniques are not flawless. One of the main concerns is the off-target effects. Two studies showed that ZFNs cleaved off-target sites in genome besides the in vitro predicted DNA sequences, which might cause chromosomal instability and genotoxicity (Gabriel et al., 2011; Pattanayak et al., 2011). In addition, even on-target effect of ZFNs can cause genotoxicity, as repair of ZFN cleavage sites also leads to frequent mutations (Lombardo et al., 2007; Cathomen and Joung, 2008) and abnormal integrations of donor DNA (Hockemeyer et al., 2009).

\section{TALEN}

TALEN was recently developed as a novel technique for gene targeting in hPSCs (Miller et al., 2011; Zhang et al., 2011). Similar to ZFNs, engineered TALENs were generated by fusing Fokl catalytic domain capable of inducing double 
strand breaks (DSBs) and TALE repeats domain to recognize specific DNA sequence (Kiefer, 2011). TALENs exhibited similar (Mussolino et al., 2011) or higher (Miller et al., 2011) cleavage activity for efficient gene targeting and fewer off-target effects to reduce nuclease-associated toxicity relative to ZFNs system (Mussolino et al., 2011). TALENs seem very promising for targeted genome engineering. Nevertheless, given that TALEN repeats are larger than that of zinc finger proteins (ZFPs), effective delivery methods should be developed to obtain higher gene targeting efficiency (Miller et al., 2011). Another unknown factor that should be considered is their off-target effects since TALENs employ a similar nuclease-based gene editing mechanism like ZFNs. Thus their potential off-target effects and genotoxicity need to be carefully examined in future studies.

\section{HDAdV}

An alternative method based on HDAdV has been shown to be highly efficient for gene editing in hPSCs with transient gene transfer efficiency as high as $\sim 100 \%$ (Suzuki et al., 2008; Liu et al., 2011b). HDAdV-based gene targeting was first reported by Suzuki et al. in 2008 (Suzuki et al., 2008), which provided a "proof of principle" evidence that this technology could be used for effective gene editing in hPSCs. Recently, we presented evidence for the advantage of HDAdV-based gene correction in patient-derived hiPSCs and mesenchymal stem cells (Liu et al., 2011b). Different from AAV-based method, HDAdV minimizes safety issues that virus vectors may bear, as the essential sequence for viral duplication and packaging is provided by a separate helper virus. By utilizing this system, we have successfully corrected mutated $L M N A$ in progeria patients-specific hiPSCs with high efficiency and (epi-)genomic integrity (Liu et al., 2011a, 2011b). This new system offers several advantages for gene manipulation in human cells. First, toxic viral elements are removed from HDAdV, therefore allowing incorporation of long homologous DNA (up to $37 \mathrm{~kb}$ ) into vector backbone (Suzuki et al., 2008). This high cloning capacity of HDAdV enables flexible use of homology arms, promoters/enhancers, selection markers, reporter genes or even combinations with other gene editing tools such as ZFNs or TALENs. Second, HDAdV gives a high efficiency in genomic editing in hPSCs (for $L M N A$ locus, the gene targeting efficiency is about $90 \%$ ), probably due to its efficient DNA delivery and long retention time in hPSCs (Liu et al., 2011b). Third, as demonstrated by successfully targeting two different mutations in $L M N A$ and subsequent single-nucleotide polymorphism (SNP) analyses, a single HDAdV (LMNA-C-HDAdV) can be potentially applied to correct over 200 different laminopathies-associated LMNA mutations (Liu et al., 2011b). Fourth, similar to ZFNs, HDAdV exhibits excellent performance in editing transcriptionally inactive genomic loci (Li et al., 2011; Liu et al., 2011b). Disadvantages of the
HDAdV-based gene correction include targeting one allele upon one round of transduction and retaining a tiny molecular footprint (FRT site) in the genome, although no evidence shows that the $F R T$ site could affect any gene function (Li et al., 2011; Liu et al., 2011b). Another concern is its relatively complicated process associated with HDAdV, which may hamper its broad range of applications.

\section{COMPARISON OF ZFN AND HDAdV}

As mentioned above, ZFN and HDAdV are two main gene editing tools utilized in hESCs and hiPSCs. Recently, three laboratories independently reported successful gene corrections in hiPSCs derived from sickle cell disease (SCD) patients using ZFNs (Sebastiano et al., 2011; Zou et al., 2011a) as well as HDAdV (Li et al., 2011). SCD is a genetic disease caused by mutations in $\beta$-GLOBIN (HBB) gene, leading to severe anemia in adults. Zou et al. utilized ZFNsbased method to generate a precise correction of $H B B$ gene in patient hiPSCs. Four hiPSC clones in which HBB mutation was precisely corrected were obtained after selection and careful examination (Zou et al., 2011a). In another study, Sebastiano et al. also applied ZFNs-based approach to correct the same mutation in hiPSCs derived from SCD patients. They obtained an average of $9.8 \%$ targeting efficiency and no random insertion was identified in all correctly targeted clones. The authors found no off-target effect within 12 most likely off-target genomic sites according to DNA sequencing, whereas complete genome should be examined to warrant a more accurate conclusion (Sebastiano et al., 2011). More recently, Belmonte group reported an efficient correction of HBB mutations in SCD-specific hiPSCs using an HDAdV-based strategy (Li et al., 2011). Indeed, all possible mutations in $H B B$ can be precisely corrected with a single HDAdV correction vector (HBB-c-HDAdV) containing whole wild-type HBB genomic sequence (Li et al., 2011). More importantly, both gene-targeting and gene-correction efficiency at $H B B$ locus in different hiPSCs lines were extremely high ( $80 \%$ to $100 \%)$, despite of the fact that $H B B$ is transcriptionally inactive in hPSCs. In addition, it was demonstrated that no random integration of $H B B-c-H D A d V$ occurred in genomic DNA, as determined by a fluorescence in situ hybridization (FISH) analysis (Li et al., 2011). All together, these novel gene-editing techniques have their own pros and cons. ZFNs-mediated gene editing strategy is capable of targeting both alleles in one targeting process without leaving molecular footprint, but may introduce unexpected DSBs and mutations in the genome. Due to a "one-step" gene knock-out or knock-in protocol, ZFNs (or TALENs) could probably be of a better choice for basic biomedical research (Kim and Svendsen, 2011). In contrast, HDAdV-based gene targeting technique exhibits a consistently high gene-targeting efficiency and leaves a possibility of modifying all potential mutations in a large genomic region, without random 
integration and (epi-)genetic aberrance (Li et al., 2011; Liu et al., 2011b). Its disadvantages of laborious construction and complex procedure may hamper its broad use in basic biomedical research. Rather, HDAdV-based technique could be a superior choice for a robust and safe strategy to correct gene mutations in patient-specific hiPSCs prior to transplantation (Kim and Svendsen, 2011).

\section{CONCLUSION AND PERSPECTIVE}

Employing genetically corrected mutation-free hiPSCs into clinical therapy is a promise of regenerative medicine (Sancho-Martinez et al., 2011). The development of robust and safe genome editing tools represents one of the most critical steps to make personalized regenerative medicine a reality. It is essential to confirm that there is no unexpected mutation in corrected hiPSCs prior to clinical transplantations. To this end, whole genome sequencing is strongly recommended for therapeutic purposes of corrected hiPSCs. It would be also interesting to examine whether it is possible to perform direct gene correction in patient somatic cells like fibroblasts with combined HDAdV and ZFN (or TALEN) strategies. In this case, desired cell types such as neurons obtained by trans-differentiation from gene-corrected somatic cells could be used for both disease study and therapeutic applications in the future (Jopling et al., 2011).

\section{ACKNOWLEDGEMENTS}

Work in the laboratory of GHL was supported by 100 Talents Program of the Chinese Academy of Sciences.

\section{ABBREVIATIONS}

AAV, adeno-associated virus vector; BAC, bacterial artificial chromosome; DSBs, double strand breaks; HDAdV, helper-dependent adenoviral vector; hESCs, human embryonic stem cells; hPSCs, human pluripotent stem cells; IDLV, integrase-deficient lentivirus; SCD, sickle cell disease; SCID-X1, X-linked severe combined immunodeficiency; SNP, single-nucleotide polymorphism; TALEN, transcription activator-like effecter nuclease; ZFN, zinc finger nuclease; ZFPs, zinc finger proteins

\section{REFERENCES}

Asuri, P., Bartel, M.A., Vazin, T., Jang, J.H., Wong, T.B., and Schaffer, D.V. Directed evolution of adeno-associated virus for enhanced gene delivery and gene targeting in human pluripotent stem cells. Mol Ther. 2011 Nov 22. DOI: 10.1038/mt.2011.255. [Epub ahead of print]

Braam, S.R., Denning, C., van den Brink, S., Kats, P., Hochstenbach, R., Passier, R., and Mummery, C.L. (2008). Improved genetic manipulation of human embryonic stem cells. Nat Methods 5, 389-392.

Bu, L., Gao, X., Jiang, X., Chien, K.R., and Wang, Z. (2010). Targeted conditional gene knockout in human embryonic stem cells. Cell
Res 20, 379-382.

Bu, L., Jiang, X., Martin-Puig, S., Caron, L., Zhu, S., Shao, Y., Roberts, D.J., Huang, P.L., Domian, I.J., and Chien, K.R. (2009). Human ISL1 heart progenitors generate diverse multipotent cardiovascular cell lineages. Nature 460, 113-117.

Buecker, C., Chen, H.H., Polo, J.M., Daheron, L., Bu, L., Barakat, T. S., Okwieka, P., Porter, A., Gribnau, J., Hochedlinger, K., et al. (2010). A murine ESC-like state facilitates transgenesis and homologous recombination in human pluripotent stem cells. Cell Stem Cell 6, 535-546.

Cathomen, T., and Joung, J.K. (2008). Zinc-finger nucleases: the next generation emerges. Mol Ther 16, 1200-1207.

Cermak, T., Doyle, E.L., Christian, M., Wang, L., Zhang, Y., Schmidt, C., Baller, J.A., Somia, N.V., Bogdanove, A.J., and Voytas, D.F. (2011). Efficient design and assembly of custom TALEN and other TAL effector-based constructs for DNA targeting. Nucleic Acids Res 39, e82.

Costa, M., Dottori, M., Sourris, K., Jamshidi, P., Hatzistavrou, T., Davis, R., Azzola, L., Jackson, S., Lim, S.M., Pera, M., et al. (2007). A method for genetic modification of human embryonic stem cells using electroporation. Nat Protoc 2, 792-796.

Davis, R.P., Ng, E.S., Costa, M., Mossman, A.K., Sourris, K., Elefanty, A.G., and Stanley, E.G. (2008). Targeting a GFP reporter gene to the MIXL1 locus of human embryonic stem cells identifies human primitive streak-like cells and enables isolation of primitive hematopoietic precursors. Blood 111, 1876-1884.

DeKelver, R.C., Choi, V.M., Moehle, E.A., Paschon, D.E., Hockemeyer, D., Meijsing, S.H., Sancak, Y., Cui, X., Steine, E.J., Miller, J.C., et al. (2010). Functional genomics, proteomics, and regulatory DNA analysis in isogenic settings using zinc finger nuclease-driven transgenesis into a safe harbor locus in the human genome. Genome Res 20, 1133-1142.

Deyle, D.R., Khan, I.F., Ren, G., Wang, P.-R., Kho, J., Schwarze, U., and Russell, D.W. (2011). Normal collagen and bone production by gene-targeted human osteogenesis imperfecta iPSCs. Mol Ther 25, 209.

Di Domenico, A.I., Christodoulou, I., Pells, S.C., McWhir, J., and Thomson, A.J. (2008). Sequential genetic modification of the hprt locus in human ESCs combining gene targeting and recombinase-mediated cassette exchange. Cloning Stem Cells 10, 217-230.

Elliott, D.A., Braam, S.R., Koutsis, K., Ng, E.S., Jenny, R., Lagerqvist, E.L., Biben, C., Hatzistavrou, T., Hirst, C.E., Yu, Q.C., et al. NKX2-5 $\left(\mathrm{e}^{\mathrm{GFP} / \mathrm{w}}\right) \mathrm{hESCs}$ for isolation of human cardiac progenitors and cardiomyocytes. Nat Methods. DOI: 10.1038/nmeth.1740. [Epub ahead of print].

Fischer, Y., Ganic, E., Ameri, J., Xian, X., Johannesson, M., and Semb, H. (2010). NANOG reporter cell lines generated by gene targeting in human embryonic stem cells. PLoS One 5, 5.

Gabriel, R., Lombardo, A., Arens, A., Miller, J.C., Genovese, P., Kaeppel, C., Nowrouzi, A., Bartholomae, C.C., Wang, J., Friedman, G., et al. (2011). An unbiased genome-wide analysis of zincfinger nuclease specificity. Nat Biotechnol 29, 816-823.

Goulburn, A.L., Alden, D., Davis, R.P., Micallef, S.J., Ng, E.S., Yu, Q. C., Lim, S.M., Soh, C.L., Elliott, D.A., Hatzistavrou, T., et al. (2011). A Targeted NKX2.1 Hesc reporter line enables identification of human basal forebrain derivatives. Stem Cells 29, $462-473$. 
Hockemeyer, D., Soldner, F., Beard, C., Gao, Q., Mitalipova, M., DeKelver, R.C., Katibah, G.E., Amora, R., Boydston, E.A., Zeitler, B., et al. (2009). Efficient targeting of expressed and silent genes in human ESCs and iPSCs using zinc-finger nucleases. Nat Biotechnol 27, 851-857.

Hockemeyer, D., Wang, H., Kiani, S., Lai, C.S., Gao, Q., Cassady, J. P., Cost, G.J., Zhang, L., Santiago, Y., Miller, J.C., et al. (2011). Genetic engineering of human pluripotent cells using TALE nucleases. Nat Biotechnol 29, 731-734.

Howden, S.E., Gore, A., Li, Z., Fung, H.L., Nisler, B.S., Nie, J., Chen, G., Mclntosh, B.E., Gulbranson, D.R., Diol, N.R., et al. (2011). Genetic correction and analysis of induced pluripotent stem cells from a patient with gyrate atrophy. Proc Natl Acad Sci U S A 108, 6537-6542.

Irion, S., Luche, H., Gadue, P., Fehling, H.J., Kennedy, M., and Keller, G. (2007). Identification and targeting of the ROSA26 locus in human embryonic stem cells. Nat Biotechnol 25, 1477-1482.

Jopling, C., Boue, S., and Izpisua Belmonte, J.C. (2011). Dedifferentiation, transdifferentiation and reprogramming: three routes to regeneration. Nat Rev Mol Cell Biol 12, 79-89.

Kamei, K., Guo, S., Yu, Z.T., Takahashi, H., Gschweng, E., Suh, C., Wang, X., Tang, J., McLaughlin, J., Witte, O.N., et al. (2009). An integrated microfluidic culture device for quantitative analysis of human embryonic stem cells. Lab Chip 9, 555-563.

Khan, I.F., Hirata, R.K., Wang, P.R., Li, Y., Kho, J., Nelson, A., Huo, Y., Zavaljevski, M., Ware, C., and Russell, D.W. (2010). Engineering of human pluripotent stem cells by AAV-mediated gene targeting. Mol Ther 18, 1192-1199.

Kiefer, J.C. (2011). Primer and interviews: Advances in targeted gene modification. Dev Dyn 240, 2688-2696.

Kim, H.W., and Svendsen, C.N. (2011). Gene editing in stem cells hits the target. Cell Stem Cell 9, 93-94.

Li, M., Suzuki, K., Qu, J., Saini, P., Dubova, I., Yi, F., Lee, J., SanchoMartinez, I., Liu, G.H., and Belmonte, J.C. (2011). Efficient correction of hemoglobinopathy-causing mutations by homologous recombination in integration-free patient iPSCs. Cell Res 34, 1350-1351.

Liu, G.H., Barkho, B.Z., Ruiz, S., Diep, D., Qu, J., Yang, S.L., Panopoulos, A.D., Suzuki, K., Kurian, L., Walsh, C., et al. (2011a). Recapitulation of premature ageing with iPSCs from HutchinsonGilford progeria syndrome. Nature 472, 221-225.

Liu, G.H., Suzuki, K., Qu, J., Sancho-Martinez, I., Yi, F., Li, M., Kumar, S., Nivet, E., Kim, J., Soligalla, R.D., et al. (2011b). Targeted gene correction of laminopathy-associated LMNA mutations in patientspecific iPSCs. Cell Stem Cell 8, 688-694.

Lombardo, A., Cesana, D., Genovese, P., Di Stefano, B., Provasi, E., Colombo, D.F., Neri, M., Magnani, Z., Cantore, A., Lo Riso, P., et al. (2011). Site-specific integration and tailoring of cassette design for sustainable gene transfer. Nat Methods 8, 861-869.

Lombardo, A., Genovese, P., Beausejour, C.M., Colleoni, S., Lee, Y. L., Kim, K.A., Ando, D., Urnov, F.D., Galli, C., Gregory, P.D., et al. (2007). Gene editing in human stem cells using zinc finger nucleases and integrase-defective lentiviral vector delivery. Nat Biotechnol 25, 1298-1306.

Miller, J.C., Tan, S., Qiao, G., Barlow, K.A., Wang, J., Xia, D.F., Meng, X., Paschon, D.E., Leung, E., Hinkley, S.J., et al. (2011). A TALE nuclease architecture for efficient genome editing. Nat Biotechnol 29, 143-148.
Mitsui, K., Suzuki, K., Aizawa, E., Kawase, E., Suemori, H., Nakatsuji, N., and Mitani, K. (2009). Gene targeting in human pluripotent stem cells with adeno-associated virus vectors. Biochem Biophys Res Commun 388, 711-717.

Mussolino, C., Morbitzer, R., Lütge, F., Dannemann, N., Lahaye, T., and Cathomen, T. (2011). A novel TALE nuclease scaffold enables high genome editing activity in combination with low toxicity. Nucleic Acids Res 39, 9283-9293.

Papapetrou, E.P., Lee, G., Malani, N., Setty, M., Riviere, I., Tirunagari, L.M., Kadota, K., Roth, S.L., Giardina, P., Viale, A., et al. (2011). Genomic safe harbors permit high $\beta$-globin transgene expression in thalassemia induced pluripotent stem cells. Nat Biotechnol 29, 73-78.

Pattanayak, V., Ramirez, C.L., Joung, J.K., and Liu, D.R. (2011). Revealing off-target cleavage specificities of zinc-finger nucleases by in vitro selection. Nat Methods 8, 765-770.

Ramachandra, C.J., Shahbazi, M., Kwang, T.W., Choudhury, Y., Bak, X.Y., Yang, J., and Wang, S. (2011). Efficient recombinasemediated cassette exchange at the AAVS1 locus in human embryonic stem cells using baculoviral vectors. Nucleic Acids Res 39, e107.

Raya, A., Rodríguez-Pizà, I., Guenechea, G., Vassena, R., Navarro, S., Barrero, M.J., Consiglio, A., Castellà, M., Río, P., Sleep, E., et al. (2009). Disease-corrected haematopoietic progenitors from Fanconi anaemia induced pluripotent stem cells. Nature 460, 53-59.

Ruby, K.M., and Zheng, B. (2009). Gene targeting in a HUES line of human embryonic stem cells via electroporation. Stem Cells 27 , 1496-1506.

Sakurai, K., Shimoji, M., Tahimic, C.G.T., Aiba, K., Kawase, E., Hasegawa, K., Amagai, Y., Suemori, H., and Nakatsuji, N. (2010). Efficient integration of transgenes into a defined locus in human embryonic stem cells. Nucleic Acids Res 38, e96.

Sancho-Martinez, I., Li, M., and Izpisua Belmonte, J.C. (2011). Disease correction the iPSC way: advances in iPSC-based therapy. Clin Pharmacol Ther 89, 746-749.

Sebastiano, V., Maeder, M.L., Angstman, J.F., Haddad, B., Khayter, C., Yeo, D.T., Goodwin, M.J., Hawkins, J.S., Ramirez, C.L., Batista, L.F., et al. (2011). In situ genetic correction of the sickle cell anemia mutation in human induced pluripotent stem cells using engineered zinc finger nucleases. Stem Cells 29, 1717-1726.

Soldner, F., Laganière, J., Cheng, A.W., Hockemeyer, D., Gao, Q., Alagappan, R., Khurana, V., Golbe, L.I., Myers, R.H., Lindquist, S., et al. (2011). Generation of isogenic pluripotent stem cells differing exclusively at two early onset Parkinson point mutations. Cell 146, 318-331.

Song, H., Chung, S.K., and Xu, Y. (2010). Modeling disease in human ESCs using an efficient BAC-based homologous recombination system. Cell Stem Cell 6, 80-89.

Suzuki, K., Mitsui, K., Aizawa, E., Hasegawa, K., Kawase, E., Yamagishi, T., Shimizu, Y., Suemori, H., Nakatsuji, N., and Mitani, K. (2008). Highly efficient transient gene expression and gene targeting in primate embryonic stem cells with helperdependent adenoviral vectors. Proc Natl Acad Sci U S A 105, 13781-13786.

Urbach, A., Schuldiner, M., and Benvenisty, N. (2004). Modeling for Lesch-Nyhan disease by gene targeting in human embryonic stem cells. Stem Cells 22, 635-641. 
Xue, H., Wu, S., Papadeas, S.T., Spusta, S., Swistowska, A.M., MacArthur, C.C., Mattson, M.P., Maragakis, N.J., Capecchi, M.R., Rao, M.S., et al. (2009). A targeted neuroglial reporter line generated by homologous recombination in human embryonic stem cells. Stem Cells 27, 1836-1846.

Yusa, K., Rashid, S.T., Strick-Marchand, H., Varela, I., Liu, P.-Q., Paschon, D.E., Miranda, E., Ordóñez, A., Hannan, N.R.F., Rouhani, F.J., et al. (2011). Targeted gene correction of a1-antitrypsin deficiency in induced pluripotent stem cells. Nature 478, 391-394.

Zhang, F., Cong, L., Lodato, S., Kosuri, S., Church, G.M., and Arlotta, P. (2011). Efficient construction of sequence-specific TAL effectors for modulating mammalian transcription. Nat Biotechnol 29, 149-153.

Zou, J., Maeder, M.L., Mali, P., Pruett-Miller, S.M., Thibodeau-
Beganny, S., Chou, B.K., Chen, G., Ye, Z., Park, I.H., Daley, G.Q., et al. (2009). Gene targeting of a disease-related gene in human induced pluripotent stem and embryonic stem cells. Cell Stem Cell 5, 97-110.

Zou, J., Mali, P., Huang, X., Dowey, S.N., and Cheng, L. (2011a). Sitespecific gene correction of a point mutation in human iPS cells derived from an adult patient with sickle cell disease. Blood 118, $4599-4608$

Zou, J., Sweeney, C.L., Chou, B.K., Choi, U., Pan, J., Wang, H., Dowey, S.N., Cheng, L., and Malech, H.L. (2011b). Oxidasedeficient neutrophils from $X$-linked chronic granulomatous disease iPS cells: functional correction by zinc finger nuclease-mediated safe harbor targeting. Blood 117, 5561-5572.

Zwaka, T.P., and Thomson, J.A. (2003). Homologous recombination in human embryonic stem cells. Nat Biotechnol 21, 319-321 